REDES- Revista hispana para el análisis de redes sociales

Vol.15, \#3, Diciembre 2008

http://revista-redes.rediris.es

\title{
El colectivo obrero ruso y la migración ${ }^{1}$
}

\author{
Markku Lonkila y Anna-Maria Salmi - University of Helsinki ${ }^{2}$
}

\section{Resumen}

El artículo analiza el colectivo de trabajadores rusos desde la perspectiva de la migración interna, un aspecto hasta ahora ignorado pero sin embargo importante puesto que la Unión Soviética y la Rusia contemporánea pueden ser consideradas como "sociedades de emigrantes". A partir de cuestionarios sobre redes y entrevistas temáticas con 38 trabajadores masculinos en la famosa factoría Kirov, en San Petersburgo, examinamos el grado en el que éstos recurren a sus compañeros de trabajo para socializarse, buscar ayuda y apoyo en la vida cotidiana. A pesar de los radicales cambios institucionales ocurridos, el colectivo de trabajadores tiene un impacto importante en la vida de los trabajadores y de los trabajadores migrantes en particular. Esto es explicado mediante un análisis del proceso de emigración en la era soviética. Careciendo de otros canales para adaptarse a la nueva vida en la metrópolis, las nuevas relaciones que los migrantes formaron en la ciudad estaban básicamente relacionadas con el lugar de trabajo. La importancia del lugar de trabajo parece ser un hallazgo trivial e inevitable pero argumentamos que esto no es así por dos cuestiones. Primero, las redes de los migrantes, incluso después de décadas de residencia en la ciudad están todavía marcadas por su pasado migratorio, no siendo obvio por qué esto tiene que ser así. Segundo, la migración por sí misma no lleva inevitablemente a que los compañeros de trabajo sean importantes, como queda ilustrado en el hecho que las redes de los migrantes finlandeses no se construyen alrededor del trabajo. Lo que es relevante no es por tanto la migración como abstracción sino las circunstancias del tipo de migración.

Palabras clave: red personal - emigración interna - apoyo informal - lugar de trabajo.

\begin{abstract}
The article analyses the Russian work collective from the perspective of internal migration, a hitherto neglected yet important aspect of studies of the work collective, given that the Soviet Union and contemporary Russia may be considered as 'societies of migrants'. Drawing on structured network questionnaires and thematic interviews with 38 male workers in the famous Kirov factory, St. Petersburg, we examine the extent to which the respondent turn to their coworkers for socialising, help and support in daily life. Despite the sweeping institutional changes brought by the transformation, the work collective continues to have an important impact in the daily life of workers, and migrant workers in particular. This is explained by an analysis of the Soviet-era migration process. Lacking other channels for adapting to the new life in the metropolis, the new ties that the migrants formed in the city were mostly related to their workplace. The
\end{abstract}

\footnotetext{
${ }^{1}$ Publicado originalmente en Europe-Asia Studies, Vol. 57, No. 5, July 2005, 681 - 703. ISSN 0966-8136 print; ISSN 1465-3427. University of Glasgow. DOI: 10.1080/09668130500126452. Traducción de Daniel Holgado Ramos.

2 Enviar correspondencia a: markku.lonkila@helsinki.fi. Los autores quisieran agradecer a Risto Alapuro, Sarah Ashwin, Anna-Maija Castrén, Michael Eve, Anja-Miina Lohiniva, Suvi Salmenniemi, Sofia Tchouikina y a los críticos anónimos sus valiosos comentarios. El estudio fue financiado por la Academia de Finlandia y el Helsinki Collegium for Advanced Studies.
} 
importance of workplace-related ties may seem to be a trivial and inevitable finding, but we argue this is not so at least in two respects. First, the migrants' networks, even after decades of residence in the city, are still marked by the migratory background, but there is nothing obvious in that they should remain so. Second, migration per se does not inevitably lead to co-workers being important, as is illustrated by the fact that the networks of Finnish migrant workers are not built around work. What matters then is not migration as an abstraction but the circumstances of the type of migration.

Key words: personal network - internal migration - social support - workplace.

Durante la era soviética, la famosa fábrica Kirov de San Petersburgo empleaba a 50.000 trabajadores. La privatización de la fábrica se inició en 1992 y hacia 1999 el número de trabajadores se había recortado a 8.000 (Grant, 1999, p.163). ¿Qué impacto han tenido estos cambios drásticos sobre la relación entre los compañeros de trabajo? ¿Significa el fuerte recorte que el colectivo obrero ${ }^{3}$, base tan apreciada de la sociedad soviética, ha quedado erosionado y que los trabajadores buscan cada vez más el apoyo fuera de las fábricas en sus esfuerzos para afrontar la vida diaria? En este artículo examinamos estas cuestiones analizando las redes personales de los trabajadores de la fábrica Kirov en San Petersburgo en el 2000. En lugar de centrarnos en las relaciones formales de producción o en la concesión de beneficios a través del colectivo, examinamos los lazos sociales informales e investigamos hasta qué punto los trabajadores rusos acuden a sus compañeros de trabajo en busca de socialización, de ayuda y de apoyo en su vida diaria. En segundo lugar, combinando temas anteriormente desconectados como migración y colectivo obrero, mostraremos que el papel actual del colectivo difiere de forma sorprendente entre aquellos que han emigrado a la ciudad en comparación con aquéllos que ya nacieron en ella.

El colectivo obrero soviético ejercía una importante función social, económica y política. La empresa soviética no sólo era una unidad de producción; era el "centro de casi todos los aspectos de la existencia social de sus empleados" (Clarke, 1999, p.57). Por ejemplo, varios servicios sociales y beneficios, como el subsidio alimenticio, las plazas de guardería, la seguridad social, las actividades culturales, deportivas y de ocio, la vivienda, se mediaban a través de colectivo obrero y su

\footnotetext{
${ }^{3}$ El término 'colectivo obrero' se puede referir tanto a toda la mano de obra de una sola empresa como a los trabajadores del entorno laboral de una persona (Ashwin, 1999a, p. 10). En este artículo el término "compañeros de trabajo" se refiere tanto a aquellos que trabajan en el mismo departamento como a aquellos que trabajan en la fábrica en general. En la práctica, estos últimos constituyen solo el $17 \%$ de todos los compañeros de trabajo citados en nuestros datos.
} 
importancia se incrementaba debido a que a menudo no existía otro modo de obtener estos beneficios básicos (Ashwin, 1999a, pp.10 - 11). Además, el colectivo era también un sistema de control social. Se exigía a cada ciudadano soviético que trabajara, pero "no era tanto la obligación de trabajar como la obligación de estar vinculado a un puesto de trabajo" (Clarke, 1999, p.57). Finalmente, el colectivo era importante a nivel social; tanto hombres como mujeres sentían un "vínculo genuino" hacia el colectivo, que les ayudaba a "huir de las tareas pesadas del hogar y les brindaba una oportunidad para la sociabilidad comunal" en las condiciones de falta de espacio de las viviendas soviéticas (Ashwin, 1999a, p.11). Al mismo tiempo, el colectivo era el lugar donde se producían varios conflictos de interés y luchas de poder, tanto entre trabajadores como entre trabajadores y capataces. Existía una jerarquía de trabajadores dentro del colectivo: por ejemplo, existía una distinción entre los trabajadores de producción básica y los trabajadores auxiliares. La edad y la experiencia formaban la base del estatus jerárquico así como las cualidades personales del trabajador individual ("el alcoholismo" y la "falta de diligencia laboral" contrapuestas al "activismo" y al "compromiso positivo con el trabajo" (Clarke, 1995a, p.8). En la cima, estaban los trabajadores más experimentados que habían demostrado su lealtad y su compromiso durante largo tiempo (Clarke, 1999, p.62; véase también Monousova y Guskova, 1996). El colectivo obrero post-soviético ha sido objeto de varios estudios recientes (Ashwin, 1998, 1999a, 1999b, 2000; Burawoy y Krotov, 1993; Clarke, 1995b, 1996a, 1996b, 1996c, 1999; Clement, 2003; Maksimov, 2000; Morrison y Schwartz, 2003; Piipponen, 2004). Estos estudios se centran en los cambios arrolladores provocados por la transformación. Los trabajadores post-soviéticos no sólo han perdido su estatus glorioso de pilares de la industria y de la economía soviéticas, también han visto restringida su autonomía al nivel básico; y con salarios reducidos y pagos a menudo retrasados, la reforma económica ha supuesto un duro golpe para ellos (Kiblitskaya, 2000, pp.100 - 101). Además, ya no pueden contar con un trabajo seguro para el resto de su vida, ya que los empresarios ahora deben "adecuar el número de empleados a las demandas de producción" (Clarke, 1999, p.74). En su excelente estudio sobre los mineros de Kuzbass, Ashwin (1999a, pp.147, 168 179) apunta dos tendencias de particular interés para nuestro estudio. Primero, presta atención al "declive social" del colectivo obrero: los trabajadores a los que entrevistó se quejaban de que su colectivo se estaba separando, cosa que suponía una evolución que no les gustaba para nada. En segundo lugar, aunque la mina 
seguía siendo importante en muchos sentidos ${ }^{4}$, los trabajadores cada vez buscaban fuera de ella las claves para su supervivencia. Empleando estrategias de supervivencia individuales, cada vez confiaban más en ellos mismos, en sus familias y amigos y en sus pequeños huertos que en su lugar de trabajo para sobrevivir. Estas relaciones, dice Ashwin (1999a, p.169), "no se persiguen a través de las relaciones sociales del colectivo obrero sino a través de las redes de familiares y amigos, que en muchos casos son independientes de las relaciones sociales del colectivo obrero inmediato".

Investigaremos estos dos temas desde la perspectiva de la migración interna, un aspecto olvidado pero importante de los estudios del colectivo obrero, puesto que la Unión Soviética y la Rusia contemporánea podrían considerarse como "sociedades de emigrantes" 5 .

A lo largo de la historia del estado soviético, masas de gente han sido desplazadas de un lado a otro - desde el campo a las ciudades para industrializar el Estado Soviético, a Siberia, al Lejano Oriente y Asia Central, a las áreas anexionadas al Estado Soviético tras la Segunda Guerra Mundial, por no mencionar el efecto de esta Guerra, durante la cual las minorías étnicas fueron deportadas lejos de su tierra y entre 20 y 25 millones de personas se fueron para huir del avance Nazi (Wegren y Drury, 2001, pp.25 - 26). Además, la población masculina se vio obligada a partir hacia destinos lejanos para servir (o para luchar) en el ejército durante varios años y los graduados y licenciados se vieron forzados a ir a trabajar a zonas remotas del país. Los ciudadanos soviéticos también se desplazaban constantemente de forma voluntaria dentro del inmenso territorio de la URSS (a menudo burlando a las regulaciones oficiales que trataban de restringir o controlar su movimiento) ${ }^{6}$. 4 La migración es un aspecto especialmente importante en el estudio de los trabajadores, porque la mayor parte de la clase trabajadora soviética viene de un entorno rural. En un censo soviético de 1991, casi todos los obreros del país habían nacido en un pueblo (Nikula, 1997, p.90).

\footnotetext{
${ }^{4}$ Por supuesto, el salario era importante. Los trabajadores podían pedir dinero prestado a la mina en caso de necesidad grave (por ejemplo, en caso de hospitalización). La mina también les suministraba productos como carbón gratis y maquinaria para la siega del heno. Las economías doméstica y empresarial se entrelazaban en muchos sentidos (Ashwin, 1999a, p.172).

${ }^{5}$ La Unión Soviética, en particular, se caracterizaba por la migración interna, ya que el desplazamiento entre la Unión Soviética y otros países durante la Guerra Fría era escaso. En las décadas de los cincuenta y los sesenta era casi imposible emigrar; en los años setenta unas 340.000 personas (especialmente judíos y ciudadanos de origen alemán) pudieron emigrar a Occidente (Fassman y Münz, 1994, p. 531).

6 Para una explicación detallada de las dicotomías "voluntario" e "involuntario", y de migración económica y política, que de hecho son dos categorías bastante artificiales, véase Pilkington (1998, pp. 3 - 22).
} 
La migración se ha estudiado de forma extensiva, especialmente en el campo de la geografía y de la población (véase por ejemplo Flowerdew, 2004), pero también en muchas otras disciplinas; revisar toda esta extensa literatura no es el objeto de este artículo (para revisiones, véase Boyd, 1989; Brown, 2002). Resulta especialmente interesante en el contexto de nuestro artículo el hecho de que los estudios sobre migración han estado dominados durante mucho tiempo por la teoría económica neoclásica (normalmente empleando un enfoque de costebeneficio individual). Estudios posteriores (p.ej.: Massey, 1990; Portes, 1995) han puesto énfasis en el papel de las redes sociales y de forma más general, en la “incrustación social, que propone que los determinantes y consecuencias del comportamiento humano como la migración se pueden comprender sólo en el contexto de las relaciones sociales y de las estructuras institucionales en las que las personas están incrustadas (en comunidades de origen y destino)" (Brown, 2002, p.7). Como apunta Brown, las migraciones y las redes están relacionadas de forma recíproca. La migración se ve afectada por la información, las ideas y los recursos incrustados en las redes (por ejemplo, la gente a menudo se desplaza hasta un destino en el que conocen a alguien), pero la migración es también "la responsable directa e indirecta de construir y transformar esta red social" (Brown, 2002, p.8). Pero no parece que el impacto de la migración en las redes sociales sea objeto de estudio demasiado a menudo (aunque véase E. Grieco, 1998; M. Grieco, 1987; Eve, 2001, 2002a).

El argumento principal propuesto por Eve (2001, 2002a) es que la migración afecta a las redes sociales. Apunta a que la migración se ve a menudo como algo que hay que explicar y sugiere que debería incluirse en la investigación como una variable sociológica (como la edad o el sexo, por ejemplo) para explicar cosas. En lugar de centrarse en los aspectos culturales o institucionales de la migración, o en los emigrantes y la recepción con la que se encuentran, Eve sugiere que se debería prestar más atención al proceso mismo de migración y a sus consecuencias. Todos los emigrantes (ya sean internos o internacionales) comparten la necesidad de reconstruir gran parte de su red social en el nuevo hogar, pero sólo cuentan con un número limitado de formas para hacerlo (Eve, 2002a, p.2) ${ }^{7}$.

\footnotetext{
7 Eve enfatiza de esta forma las similitudes entre la migración interna e internacional, aunque reconozca la particularidad de la migración internacional. La Unión Soviética era un híbrido interesante porque la migración interna contaba con muchas características típicas de la migración internacional, como las restricciones a la hora de elegir el lugar de residencia.
} 
Las observaciones de Eve son especialmente relevantes en el contexto postSoviético, porque, como mostraremos más adelante, la migración marca de forma crucial la historia personal de los emigrantes de este estudio y tiene implicaciones importantes para sus vidas diarias, incluso décadas después de que hayan emigrado a la ciudad. Existen estudios sobre migración en la Rusia post-soviética", pero normalmente se centran en la migración internacional o la "re-migración" étnica desde los estados soviéticos a Rusia (p.ej.: el extenso estudio de Pilkington, 1998; Zayonchkovskaya, 1999). La "fuga de cerebros" hacia Rusia de aquellos técnicamente cualificados y los movimientos Este-Oeste también se han estudiado, mientras que la migración interna es un tema relativamente olvidado a pesar de constituir el $80 \%$ de la migración rusa (Wegren y Drury, 2001, pp.15 - 16). El estudio de Wegren y Drury sobre migración interna es uno de los pocos al respecto (véase también Badyshtova, 2002; Mitchneck y Plane, 1995; Wegren, 1995). Pero el objetivo de estos estudios de migración interna es distinto del nuestro en el sentido que tratan de explicar los factores determinantes y la dirección de la migración actual. Por lo que sabemos, hay pocos estudios en Rusia que usen la migración interna como una variable de fondo para los varios procesos sociales, ya no digamos el trabajo.

En la siguiente sección presentamos el método y los datos que hemos usado para este estudio. Luego describimos las características particulares de la migración soviética, tras lo cual examinamos en detalle cómo la relación con el colectivo obrero personal de cada uno es distinta para los emigrantes en comparación con los trabajadores nacidos en San Petersburgo. En la sección final discutimos nuestros resultados y hacemos sugerencias para próximas investigaciones.

\section{Datos y métodos}

Gran parte de las recientes investigaciones interesantes sobre la sociedad postsocialista se han centrado en los mecanismos y procesos a nivel popular. Burawoy y Verdery (1999), por ejemplo, han alentado a los investigadores a echar una "mirada etnográfica" a la vida cotidiana post-socialista. Nosotros nos unimos a aquellos que estudian a la sociedad rusa desde una "micro-perspectiva", pero nuestro enfoque difiere de los estudios etnográficos porque incluye un análisis explícito y sistemático de las redes personales de nuestros sujetos. La principal

\footnotetext{
8 Ejemplos de estudios recientes sobre migración en otros países post-socialistas aparte de Rusia incluyen estudios de migración en Estonia (Kulu y Billari, 2004; Sjöberg y Tammaru, 1999) y Alemani (Kemper, 2004); de regreso migratorio étnico a Estonia (Kulu y Tammaru, 2000) y Alemania (Bauer y Zimmermann, 1997) y sobre migración laboral en el contexto de Albania (Nicholson, 2004).
} 
preocupación de nuestro estudio de redes no es la organización formal o informal de la producción, si no la importancia social de las relaciones laborales (véase también Lonkila, 1998). Esta importancia se mide, por ejemplo, en términos de frecuencia de socialización con un compañero de trabajo fuera de éste o en términos de apoyo social recibido de los compañeros de trabajo. Argumentamos, en primer lugar, que la importancia de las relaciones laborales se puede entender de mejor forma estudiando las relaciones de los sujetos con sus compañeros de trabajo sin dejar de examinar al mismo tiempo también otro tipo de relaciones sociales, como aquellas con familiares, amigos y vecinos (Gribaudi, 1998; Eve, 2002b; Lonkila, 1999a). Es decir, sin restringir el estudio a los vínculos sociales en el lugar de trabajo, centrados en individuos y que a menudo se extienden más allá de las paredes de la fábrica.

En segundo lugar, el estado actual de las redes se explica explorando los procesos por los cuales se forman. Siguiendo la sugerencia de Eve (2002a), damos énfasis al impacto de un origen migratorio en la formación de las redes actuales de nuestros sujetos.

Nuestro estudio se llevó a cabo en las instalaciones de la fábrica Kirov en San Petersburgo, una de las plantas metalúrgicas más famosas de la Unión soviética y de la Rusia post-soviética. Establecida como una fundición estatal en 1789, se trasladó a su ubicación actual en 1801, donde la compró un oficial retirado llamado Ivanovich Putilov en 1868. En la era Soviética, la "fábrica roja Putilov" fue rebautizada en honor del secretario del partido en Leningrado, Sergei Kirov, en 1932. En su momento de auge, la fábrica Kirov empleaba a unos 50.000 trabajadores y producía maquinaria pesada, como tanques y tractores. Durante el proceso de privatización, iniciado en 1992, se recortó el personal y en 1999 la planta tan solo contaba con 8.000 trabajadores (Grant, 1999, pp. 21, 163; véase también Miroshnichenko y Maksimov, 1994, para un informe sobre el proceso de privatización de la planta Kirov). De todas formas, sigue siendo una de las mayores fábricas de la ciudad, con unas instalaciones impresionantes que ocupan $188 \mathrm{Ha}$, situada en el distrito Kirov de San Petersburgo. La fábrica está gestionada en forma de holding con 32 subsidiarias que alquilan partes de la planta y maquinaria a la sociedad matriz (Piipponen, 2002). 
Nuestros datos vienen de 50 trabajadores, 12 de ellos mujeres, entrevistados en uno de los seis departamentos de la fábrica de tractores Kirov en invierno de 2000. Forman parte de unas redes que agrupan a 711 miembros en total ${ }^{9}$. La proporción de hombres y mujeres en nuestros datos es exactamente la misma que en todo el departamento. Como nuestro estudio original no se centraba en la migración, no hay ninguna mujer nativa y el número de nativos varones es menor que el número de emigrantes varones. La importancia de la migración surgió mientras analizábamos los datos y decidimos restringir nuestro estudio a los trabajadores varones para poder controlar el género. Por lo tanto los datos utilizados en este estudio vienen de 38 trabajadores varones, 28 de los cuales eran emigrantes y 18 eran nacidos en la ciudad (nativos) y con 392 y 121 miembros en sus redes respectivamente ${ }^{10}$. Obtuvimos información para cada sujeto, como edad; ocupación; obligaciones laborales; estado civil; tiempo de residencia en San Petersburgo; tiempo de empleo en la fábrica e información sobre las personas que vivían en su hogar, padres e hijos ${ }^{11}$. La mayoría de los entrevistados tenían entre 40 y 50 años (la media era de 48 años). Siete habían trabajado en la fábrica durante menos de 4 años, y de los restantes 31, entre 16 y 53 años. De forma ocasional, contrastaremos nuestros hallazgos con aquellos basados en los datos recopilados en Helsinki en la primavera de 2003. Estos datos contienen información sobre 19 trabajadores varones del metal finlandeses y los 190 miembros de sus redes $^{12}$.

La información sobre las redes personales de trabajadores se obtuvo a través de un cuestionario adaptado de la encuesta de redes de Claude Fischer (1982). De forma más precisa, las redes se construyeron con la ayuda de diez "generadores de nombre" centrados en distintas formas de apoyo y sociabilidad en la vida diaria. Se preguntó a los trabajadores con quién hablaban sobre trabajo (generador de nombre 1, gn1); a quién pedirían opinión a la hora de tomar una decisión importante (gn2); con quién compartían una afición común (gn3) o con quién

\footnotetext{
${ }^{9}$ La cifra total de trabajadores del departamento era de 297. Los datos de la fábrica Kirov se recogieron en el transcurso del proyecto "Cultura cívica y nacionalidad en el noroeste de Rusia, Estonia y Finlandia", financiado por la Academia de Finlandia y las Universidades de Helsinki y Joensuu y dirigido por Ilkka Liikanen del Karelian Institute en la Universidad de J oensuu.

${ }^{10}$ Como los encuestados trabajaban en el mismo departamento, los miembros de las redes citados se solapan (p.ej.; un trabajador en particular es citado por varios encuestados).

11 Para una descripción completa de los datos recopilados véase Lonkila y Piipponen (2002). Para estudios sustanciales usando este método, véase el volumen Beyond Post-Soviet Transition (Alapuro et al., 2004)

12 Los datos finlandeses se recopilaron como parte del proyecto "Rusia, Finlandia y la Globalización en una microperspectiva", financiado por la Academia de Finlandia y dirigido por Markku Lonkila en el Helsinki Collegium for Advanced Studies, Universidad de Helsinki.
} 
pasaban tiempo libre (gn4); quién podía ayudarles con cosas como reparar aparatos domésticos o el coche (gn5); quién podía ayudarles a cuidar a los niños o dejarles utensilios de cocina (gn6); a quién le podían pedir una suma considerable de dinero (gn7); de quién habían recibido favores en los últimos 3 años (gn8) y con quién habían ido a reuniones o manifestaciones o huelgas (gn9). Para completar la lista, se les preguntó si había alguien importante que había quedado fuera $(\operatorname{gn} 10)^{13}$.

La lista total de nombres aportada por cada sujeto como respuesta a estos generadores de nombre constituye su red personal. Se les pidió información detallada sobre cada miembro de la red mencionado, incluyendo edad; ocupación; lugar de nacimiento y de residencia; tipo de duración de la relación entre el sujeto y el miembro de la red y cómo se conocieron. Finalmente, se llevó a cabo una entrevista temática con cada sujeto para recopilar un informe cronológico de su vida con la descripción de acontecimientos significativos (lugar de nacimiento; escuela; servicio militar; cambios de residencia e migración a Leningrado; trabajo; matrimonio). Además se les preguntó sobre el trabajo hoy y las condiciones de vida; las relaciones sociales; la participación en actividades sociales y políticas; el ocio y las preocupaciones y expectativas para el futuro.

Puesto que nuestros datos no son estadísticamente representativos, llevamos a cabo comparaciones cuantitativas sólo para revelar diferencias interesantes entre emigrantes y nativos. La veracidad de nuestros argumentos depende de la combinación de datos de red estructurada con datos cualitativos de la formación de las redes a medida que aparecen en la historia vital de nuestros sujetos.

\section{El carácter particular de la migración soviética}

Como todos nuestros sujetos emigrantes se trasladaron a la ciudad durante el régimen soviético, describiremos brevemente la naturaleza de la migración soviética en esta sección con el objeto de aclarar el contexto en que la migración tuvo lugar. La migración soviética tenía varias características distintivas que la convertían en un caso especial. Un factor importante a la hora de impulsar la migración hacia los centros urbanos era la diferencia de calidad de vida ente el campo y la ciudad. En su estudio de la migración a Leningrado en los años treinta, Vitukhnovskaya encontró tres razones principales por las que los emigrantes se

\footnotetext{
13 Para cada generador de nombre el encuestado podía nombrar a tanta gente como quisiera. Sólo cuando el encuestado mencionaba demasiados nombres se le pedía que se limitara a los más
} 
trasladaban a la ciudad: primero, se vieron forzados a dejar el campo para evitar el hambre, la colectivización, la expropiación de los kulaks, el desempleo y otras circunstancias difíciles. En segundo lugar, se vieron "empujados" hacia el centro industrial, cultural y científico que era Leningrado con el fin de mejorar sus estándares de vida. Un tercer grupo se había trasladado porque les habían enviado a la ciudad a estudiar (Vitukhnovskaya, 2000, p.113). En una encuesta realizada en Novgorod en 1983-1984, los dos motivos principales para emigrar a las ciudades eran el deseo para conseguir un mejor estándar de vida y el de continuar la educación (Osipov, 1988; véase también Dolgikh, 1996). Las ciudades en general, y Leningrado y Moscú en particular, ofrecían una mejor selección de bienes materiales y entretenimiento cultural: museos, cines, institutos educativos, etc. (Zaslavsky, 1982, pp.140 - 141). A lo largo de su historia, la ciudad de San Petersburgo - Leningrado ha recibido emigrantes provenientes en su mayoría del campo para industrializar el país (véase por ejemplo, Vitukhnovskaya, 2000, pp. 104 - 105). Sin embargo, debido al sistema de pasaportes internos, desplazarse desde el campo no era fácil, como tampoco lo era establecerse en la ciudad ${ }^{14}$. Para esto segundo, era necesaria una propiska, un sello en el pasaporte que indicaba el lugar permitido de residencia. La propiska no sólo era imprescindible para conseguir trabajo legal sino para casi todos los aspectos de la vida diaria como la vivienda, la asistencia sanitaria, la educación $y$, en caso de racionamiento de productos alimenticios, para conseguir las cartillas (Berzin y Panova, 1990; Höjdestrand, 2003; Zemtsov, 1991, pp. 268 - 270) ${ }^{15}$. Conseguir una propiska en la era Soviética era difícil. Morton describe la situación a finales de los setenta:

La posibilidad de recibir permisos para desplazarse a Moscú, Leningrado o Kiev sin el patrocinio oficial o sin piso paras intercambiarlo en otra ciudad es casi nula. Incluso con estas condiciones, hay numerosos obstáculos que

importantes.

14 El sistema de pasaporte interno se reinstauró en 1932 para controlar a la población en general y para regular la creciente migración del campo hacia las ciudades causada por la colectivización. La "pasaportización" (pasportizatsiya) del país dividió a los ciudadanos soviéticos en dos clases: los que recibían el pasaporte automáticamente al cumplir los 16 y los que legalmente tenían derecho a pedir un pasaporte cuando dejaban las granjas colectivas - básicamente ciudadanos de zonas rurales - pero que a la práctica tenía pocas posibilidades de recibir uno. Aunque el sistema se relajó más adelante, las características esenciales se mantuvieron hasta 1976, cuando los habitantes del las zonas rurales consiguieron derechos similares a los de los otros ciudadanos soviéticos (Popov, 1995a, 1995b; véase Fitzpatrick, 1994, pp. 92 - 102).

15 El sistema de propiska fue abolido oficialmente 1993 y reemplazado por un registro en una dirección fija, aunque en lenguaje coloquial la gente siguió hablando de la propiska (Höjdestrand, 2003; Pilkington, 1998, p. 40). En la práctica, el sistema sigue bastante vigente; aunque ya no es una precondición formal para conseguir empleo, la mayoría de los trabajadores lo necesitan (Höjdestrand, 2003), como las autoridades locales que tratan con emigrantes (Pilkington, 1998, pp. 41, 92, 101). Debido a la discrepancia entre la ley federal y las prácticas locales, se necesita una propiska para poder residir en una nueva localidad y en las grandes ciudades sigue siendo difícil (o caro) obtener una (Wegren y Drury, 2001, p. 19). 
superar. Por supuesto, cuánto más prestigiosa la posición o mayor la demanda por sus habilidades o cuanto mayor su rango en la jerarquía del partido, mayores opciones tendrá. Los trabajadores con poca o ninguna formación pueden conseguir un puesto en una fábrica necesitada de personal siempre que haya camas de albergue (Morton, 1980, p.238).

Desde el estudio de Morton, los académicos han debatido si los esfuerzos del estado soviético por regular la migración interna dieron resultado o no: Buckley (1995) habla del "mito de la migración dirigida" señalando que las autoridades era incapaces de controlar el crecimiento de las grandes ciudades o detener el abandono de las zonas rurales, mientras que Gang y Stuart (1999) ponen énfasis en que las restricciones todavía tenían importancia porque las ciudades restringidas crecían más lentamente que las no restringidas. Sin embargo, podemos concluir, por lo menos que "las políticas oficiales del gobierno y las restricciones no eran eficaces del todo" (Wegren y Drury, 2001, p. 117).

Aunque era muy difícil obtener una propiska de una ciudad cerrada, mucha gente sabía cómo saltarse las reglas y buscaban formas legales, semi-legales o ilegales para obtener una (Buckley, 1995, p. 905).

Normalmente se citan el blat, el soborno o los matrimonios de conveniencia (véase por ejemplo Buckley, 1995, pp. 905-906; Höjdestrand, 2003; Ledeneva, 1998, pp. 30 - 31; Rotkirch, 2000, p. 82). Aún más, la escasez crónica de mano de obra industrial hacía que fuera relativamente fácil encontrar empleo y una forma oficial para los ciudadanos de las zonas rurales de entrar en la ciudad en la era soviética era ganarse el estatus de limitchik (Buckley, 1995, p. 905; Höjdestrand, 2003). Las grandes fábricas tenían una cuota de trabajadores asignada; éstos solían tener menos de 30 años y se reclutaban a través de campañas especiales (Loeber, 1984). Muchos de nuestros sujetos fueron reclutados cuando estaban en el ejército o en su escuela de formación profesional. Los limitchiki obtenían un permiso temporal para vivir en la ciudad durante el tiempo que duraba su contrato (para uno de los encuestados, esta propiska temporal duró diez años). Durante este tiempo, como quedaban excluidos de la lista de espera para una vivienda, dependían totalmente de su puesto de trabajo. Después de diez años, tenían derecho según la ley a una propiska permanente, que se podía obtener antes siempre que se hubiera conseguido un apartamento o habitación kommunalka a través de su puesto de trabajo (Höjdestrand, 2003). Muchos limitchiki vivían en albergues y trabajaban en tareas manuales, que los nativos consideraban de poco prestigio (Loeber, 1984). Según una estimación no oficial de mediados de los años 
setenta, el $15 \%$ de la mano de obra total en las grandes ciudades eran limitchiki (Zaslavsky, 1982, p. 146).

\section{El impacto de la migración en las redes hoy}

Mientras que el entorno migratorio soviético era especial en muchas formas, el objetivo de nuestro artículo no es descubrir las razones que llevaron a nuestros encuestados a mudarse a Leningrado o cómo llegaron aquí si no que, independientemente de sus intenciones, nos interesa saber qué pasó con los trabajadores una vez habían llegado ${ }^{16}$. Con el objeto de examinar lo que significa ser un emigrante en una gran ciudad como Leningrado o San Petersburgo, comenzaremos por examinar la historia personal de Vladimir (Spb205) ${ }^{17}$. Vladimir, un trabajador de 54 años nacido en el Óblast de Volograd, se trasladó, durante su infancia, al Óblast de Moscú, donde asistió a la escuela primaria y a la escuela de formación profesional. Tras finalizar sus estudios de formación profesional, ingresó en el ejército, desde donde le "trasladaron" a la fábrica Kirov, una oferta que estuvo encantado de aceptar, puesto que no tenía ninguna gana de regresar a su pueblo. En Leningrado, primero vivió en el dormitorio masculino de la fábrica, comenzó a trabajar y participó activamente en las actividades de sindicatos y Komsomol. A los pocos años conoció a su esposa, I rina, que trabajaba en el mismo taller y vivía en el dormitorio femenino. Pronto celebraron su boda en el dormitorio de Vladimir - ¡Y muy bien que la celebramos!- y pronto nacería su hijo Sergei. Al año siguiente les concedieron una habitación comunitaria de la fábrica, en la que vivieron siete años. Cuando sus gemelas Elena y Mariya nacieron, la familia recibió un apartamento de tres habitaciones del ayuntamiento: "Bueno, estaba en lista de espera en el Ispolkom (el comité ejecutivo) y nos declararon aptos (para concesión)... Gracias a una resolución por la cual aquellos con gemelos tenían derecho a un piso". En el momento de la entrevista, Vladimir estaba satisfecho con su vivienda: "El piso es bonito y está en un buen barrio".

En el momento de realizar el estudio, la red de Vladimir estaba formada por 15 personas (Tabla 1). La red de apoyo de Vladimir tenía tres componentes principales: familia, trabajo y vecindario, pero de hecho, los tres medios sociales estaban conectados con su puesto de trabajo, la fábrica Kirov, donde conoció a su mujer (familia) y donde se establecieron al principio - incluso obtuvo un dacha de

\footnotetext{
16 Este artículo no trata el tema de la migración como fuente de identidad.

17 Se han utilizado pseudónimos. Algunos nombres geográficos se han cambiado para mantener el anonimato de los encuestados.
} 
la fábrica en 1990. Por ello no es de extrañar que considerase que le debía mucho a la fábrica Kirov. “En primer lugar, recibí una educación. Conseguí una familia. Encontré a una persona cercana. Y sigo trabajando aquí". La historia de Vladimir es muy típica y parecida a las historias de muchos otros emigrantes en nuestros datos. De hecho, a veces uno tiene la sensación de estar leyendo la misma historia una y otra vez: primero, comparte habitación en el dormitorio de la fábrica, luego conoce a su esposa en el dormitorio o en el trabajo, luego llega el primer hijo y la familia recibe una habitación kommunalka. Pasan las décadas, los niños crecen y finalmente la familia recibe un piso de la fábrica o del ayuntamiento. En este caso, la consideran una buena vivienda; si no, sienten rencor y un sentimiento de injusticia por no haber sido declarados aptos para obtener un piso separado -el análisis de Ashwin sobre la concesión personalizada y discrecional de recursos dentro del colectivo es muy completo (Ashwin, 1999a). Pero lo importante es que los recursos de vivienda de la fábrica eran cruciales para los emigrantes y la fábrica determinaba su alojamiento de modo significativo. Esto tenía implicaciones para las redes actuales.

Trazar una historia típica similar para los nativos es mucho más complicado, principalmente porque la fábrica no estructuraba sus vidas de la misma forma. Algunas características, como vivir en un dormitorio, ya no aparecen porque los lugareños ya tienen una vivienda, normalmente la de sus padres. Otros "criterios", como obtener una vivienda de la fábrica, se cumplían sólo para algunos y sólo uno de los encuestados había conocido a su esposa en el trabajo. Aún más importante, es difícil encontrar a un solo individuo que cumpliera todos estos "criterios" y no había ruptura en la vida social del nativo porque jamás se había desplazado. A primera vista, el nativo Andrei (Spb308) es, de hecho, muy similar a los emigrantes. Conoció a su mujer en el trabajo y en una época llegó a vivir en la kommunalka de la fábrica. Era un kirovets de segunda generación (sobre dinastías de trabajadores en la fábrica Kirov véase Tkach, 2001) y sentía que el colectivo era muy importante para él: "es mi círculo". Pero cuando observamos su red y su historia personal, emergen diferencias importantes; jamás vivió en el dormitorio de la fábrica y más adelante se mudó de su habitación comunal a la de su esposa. Más importante aún, a nivel de redes emerge otro círculo importante: su familia - no sólo su mujer, hijo y nieto, sino también su nuera, su hermana, su marido, su tía y tres primos; todos ellos vivían en San Petersburgo- formaba parte de su red de apoyo, más diversa y menos centrada en el trabajo. 


\begin{tabular}{llccc}
\hline Nombre & \multicolumn{1}{c}{ Tipo de relación } & $\begin{array}{c}\text { Origen de } \\
\text { la relación }\end{array}$ & $\begin{array}{c}\text { Duración del } \\
\text { contacto (años) }\end{array}$ & $\begin{array}{c}\text { Lugar de } \\
\text { residencia }\end{array}$ \\
\hline Irina & Esposa & Trabajo & 27 & San Petersburgo \\
Elena & Hija & Familia & 21 & San Petersburgo \\
Mariya & Hija & Familia & 21 & San Petersburgo \\
Sergei & Hijo & Familia & 27 & San Petersburgo \\
Ivan & Compañero de trabajo, amigo & Trabajo & 25 & San Petersburgo \\
Gennadii P. & Compañero de trabajo & Trabajo & 32 & San Petersburgo \\
Boris & Compañero de trabajo, amigo & Trabajo & 31 & San Petersburgo \\
Gennadii K. & Compañero de trabajo & Trabajo & 22 & San Petersburgo \\
Andrei & Compañero de trabajo & Trabajo & 10 & San Petersburgo \\
Igor & Compañero de trabajo, amigo & Trabajo & 30 & San Petersburgo \\
Tamara & Compañero de trabajo & Trabajo & 14 & San Petersburgo \\
Alena & Vecino & Barrio & 19 & San Petersburgo \\
Anna & Vecino & Barrio & 19 & San Petersburgo \\
Svetlana & Vecino & Barrio & 19 & San Petersburgo \\
Ekaterina & Suegra & Su esposa & 28 & Óblast de Kalinin \\
\hline
\end{tabular}

Tabla 1. Red personal de Vladimir.

Afirmamos que las redes de los emigrantes se centran mucho más alrededor al lugar de trabajo que las de los encuestados que nacieron en San Petersburgo. Ilustraremos esto centrándonos en siete indicadores derivados de los datos de nuestra red (Piipponen 2004 usó indicadores similares por primera vez en su estudio de las diferencias generacionales entre trabajadores en una comunidad de la Carelia rusa). Primero, examinaremos el lugar de trabajo como emplazamiento para establecer las relaciones sociales (indicador 1 ) y, de forma más específica, como emplazamiento para conocer a la futura esposa (indicador 2). Entonces nos centraremos en la proporción de compañeros de trabajo en las redes de los encuestados (indicador 3) e investigaremos si estos compañeros de trabajo también se veían fuera del trabajo (indicador 4). Más aún, analizaremos la proporción de estos miembros de red que son, de forma simultánea, compañeros de trabajo y amigos como proporción de compañeros de trabajo (indicador 5) y de todos los amigos (indicador 6) mencionados. Finalmente, examinaremos hasta qué punto estos compañeros de trabajo se dan apoyo material uno al otro (indicador 7 ). De este modo, todos estos indicadores miden el papel de los compañeros de trabajo en términos de sociabilidad y de apoyo social. Para cada indicador, compararemos a los trabajadores emigrantes con aquellos que nacieron en la ciudad (nativos) para poder mostrar que la "migración variable" importa y que el lugar de trabajo es más significativo para los emigrantes que para los nativos. Trataremos de aclarar los mecanismos que conforman la relación entre el proceso migratorio y el lugar de trabajo, a partir de nuestros datos. 


\section{EI lugar de trabajo como emplazamiento para establecer lazos sociales}

¿Qué ocurrió en la vida social de los emigrantes cuando comenzaron una nueva vida en Leningrado? El primer indicador analiza hasta qué punto el lugar de trabajo funciona como escenario para establecer relaciones sociales. Descubrimos que el $42 \%$ de las redes de los emigrantes se establecieron en el trabajo, mientras que entre los lugareños el porcentaje es tan solo de $22 \%{ }^{18}$. Por lo tanto, el lugar de trabajo era un campo mucho más influyente para los emigrantes que para los nativos. El emigrante Sergei (Spb208), por ejemplo, llegó a la fábrica desde el ejército a principios de los setenta; como no quería volver al kolkhoz ucraniano donde había nacido, aceptó la oferta y se trasladó a Leningrado. En el momento de realizar este estudio, la red de Sergei consistía en nueve personas, cinco de las cuales había conocido en el trabajo. Cuatro eran compañeros de trabajo que había conocía desde hacía más de 20 años (eso significa que los conoció inmediatamente después de trasladarse a la ciudad) y uno era un vecino suyo. Viktor (Spb302), un trabajador emigrante de 50 años nacido en Ucrania, mencionó a varias personas que había conocido primero en el trabajo. Sólo uno era un compañero de trabajo; la mayoría eran sus vecinos (que probablemente habían trabajado en la Kirov pero ya lo habían dejado). También conoció a su esposa Marina en el trabajo:

Al principio vivía en el dormitorio de la fábrica. Nos casamos allí. Ella estaba embarazada y el niño iba a nacer en una o dos semanas. Mi esposa trabajaba en el mismo taller que yo.

Viktor no es el único emigrante entre nuestros sujetos que conoció a su esposa en el trabajo. Como muestra el segundo indicador, para nuestros emigrantes el lugar de trabajo era el principal canal para conocer a sus esposas, ya fuera de forma directa (en el trabajo) o indirecta (en el dormitorio o a través de otro compañero): más de la mitad de los encuestados casados o que habían estado casados (52\%) conocieron a su esposas en el trabajo, mientras que sólo el $14 \%$ de los nativos lo habían hecho ${ }^{19}$.

\footnotetext{
18 Las cifras absolutas de emigrantes eran 162 de 392 miembros de red y las de nativos eran 27 de 123.

19 Estas cifras reflejan aquellos que estaban casados (tres emigrantes y tres nativos no lo estaban). Las cifras absolutas eran 13 de 25 que se conocían en el trabajo en el caso de los emigrantes y 1 de 7 en el de los nativos.
} 


\section{Proporción de compañeros de trabajo en las redes}

Una red personal consiste típicamente en los miembros de la familia, amigos, conocidos, vecinos y -en el caso de que el sujeto trabaje- compañeros de trabajo. El tercer indicador se centra en la composición de las redes. ¿Cuántos compañeros de trabajo se mencionan en las redes de los emigrantes comparados con las de los nativos? En la Tabla 2 presentamos las proporciones de los distintos tipos de integrantes de las redes.

\begin{tabular}{lcccc}
\hline Tipo de relación & Emigrantes & $\begin{array}{c}\text { \% de miembros } \\
\text { de red }\end{array}$ & Nativos & $\begin{array}{c}\text { \% de miembros } \\
\text { de red }\end{array}$ \\
\hline Familiar & 127 & 32 & 46 & 37 \\
Amigo/conocido & 130 & 33 & 35 & 28 \\
Compañero de trabajo & 149 & 38 & 24 & 20 \\
Vecino & 63 & 16 & 24 & 20 \\
Otros & 34 & 9 & 11 & 9 \\
N de miembros en la red & 392 & 128 & 123 & $114 *$ \\
\hline
\end{tabular}

Tabla 2. Composición de las redes de trabajadores nativos y emigrantes.

* Nota: Debido al solapamiento de categorías (un miembro de la red puede ser, por ejemplo, compañero de trabajo y vecino al mismo tiempo), el porcentaje sobrepasa el 100. Por la misma razón, las sumas de distintos tipos de relaciones (503 para emigrantes y 140 para nativos) excede el número de miembros de red

Como muestra la Tabla 2, los emigrantes contaban con muchos más compañeros de trabajo en sus redes ( $38 \%$ de todos los miembros de las redes) que los nativos $(20 \%)$. Boris (Spb405), un trabajador de 33 años nacido en el Óblast de Voronezh, es un ejemplo de trabajador emigrante ruso con numerosos compañeros de trabajo en su red. Boris llegó a Leningrado a mediados de los ochenta y desde entonces había trabajado en la Kirov. En el momento de realizar el estudio su red consistía en 18 personas, incluidos nueve compañeros de trabajo: dos de ellos de una edad similar a la suya, el resto mayores. Mencionó a algunos de ellos cuando se le pidió que diera una lista de aquellos con los que podía hablar de trabajo. Con algunos compartía una afición (la pesca), con otros se socializaba después del trabajo y uno le ayudaba con pequeñas reparaciones ${ }^{20}$. Otro ejemplo es Yurii (Spb305), un emigrante del Óblast de Novgorod que había estado trabajando en una fábrica desde mediados de los sesenta. Mencionó a siete compañeros de trabajo en su red 
de 14 miembros: cuatro eran personas con las que hablaba de trabajo y con tres pasaba tiempo fuera del trabajo. En general, afirmaba que el colectivo era bueno, ya que las relaciones con sus compañeros eran muy buenas y cálidas. No estaba solo: aunque algunos encuestados se lamentaban de que las relaciones habían cambiado con los años, casi todos (una excepción) caracterizaban al colectivo como "bueno", "normal", "amistoso"; tanto lugareños como emigrantes y tanto recién llegados como trabajadores experimentados.

\section{Quedar con compañeros de trabajo fuera del trabajo}

El cuarto indicador mide si los encuestados también quedaban con sus compañeros de trabajo fuera del trabajo. Un gran número tanto de emigrantes como nativos lo hacían, pero, una vez más, los emigrantes tenían más contactos de este tipo (quedaban con el $54 \%$ de sus compañeros de trabajo fuera del trabajo), mientras que los nativos sólo quedan con el $38 \%$ de los compañeros de trabajo fuera del trabajo $^{21} .19$ La bebida estructura la sociabilidad de los hombres fuera del trabajo (a veces dentro) en Rusia. Aquí unos extractos de las entrevistas con los emigrantes Mikhail, Oleg y Valerii al respecto:

Entrevistador: Dime qué haces (con tus compañeros de trabajo fuera del trabajo).

Mikhail (Spb108): No, no quiero. (Se ríe)... Sinceramente, no vamos al teatro.

Entrevistador: ¿Y dónde vais?

Mikhail (Spb108): A la cervecería (pivbar).

Oleg (Spb207): Bueno, no bebemos té. Esperamos a que termine nuestro turno.

Valerii (Spb508): No somos de una coral, te lo aseguro... Vamos al bar (zabegalovka)

I ban hasta un lugar cercano - una cafetería o un pub barato- a beber vodka, sobretodo si era el cumpleaños de alguien (para leer sobre la importancia de los cumpleaños en Rusia, véase Salmi, 2000). Ashwin señala que el colectivo obrero es un punto de referencia crucial tanto para hombres como para mujeres, pero de distinto modo. Para las mujeres, el colectivo era importante porque era una fuente vital de apoyo emocional y una "segunda familia". Los hombres, por otra parte, casi nunca utilizaban estas expresiones "femeninas"; en lugar de esto, el colectivo les

\footnotetext{
20 En general, tres cualidades - hablar de trabajo, socializarse fuera del trabajo y dar o recibir apoyo material- eran los indicadores donde más se mencionaba a los compañeros de trabajo en San Petersburgo.

${ }^{21}$ En cifras absolutas, 81 de 149 quedaban fuera del trabajo en el caso de los emigrantes, a diferencia de los 9 de 24 en caso de los nativos.
} 
ofrecía un "alivio" mediante el ritual de beber acompañados (Ashwin, 1999a, pp. 147-151). Del mismo modo, nuestros emigrantes varones mencionados anteriormente consideraban la bebida como una negación de las formas "culturales" y femeninas de interacción como el teatro, tomar té y cantar en un coro (véase también Kiblitskaya, 2000, sobre cómo beber con los compañeros de trabajo es un componente importante de la identidad masculina).

\section{Compañeros de trabajo y amigos y amigas como compañeros de trabajo}

Los compañeros de trabajo de uno no son necesariamente sólo compañeros de trabajo, si no que pueden tener otras funciones. A través de los indicadores cinco y seis examinaremos si los compañeros de trabajo de nuestros sujetos también eran sus amigos. Cuando observamos a toda la gente clasificada como compañeros de trabajo y examinamos cuántos de ellos también han sido clasificados como amigos, vemos otra vez diferencia entre los emigrantes y los nativos: el $34 \%$ de compañeros de trabajo de emigrantes contra el $21 \%$ en los nativos ${ }^{22}$.

Todavía más interesante, cuando echamos un vistazo a aquellas personas clasificadas como amigos, y examinamos el porcentaje de compañeros de trabajo entre todos los amigos (más que amigos entre compañeros de trabajo), surge una diferencia importante. Para los emigrantes, el 59\% de todos los amigos son también compañeros de trabajo, mientras que en los nativos sólo es el $16 \%{ }^{23}$. Para poder ilustrar cómo se entrelazan las categorías de "amigo" y "compañero de trabajo", echemos un vistazo a los amigos y compañeros de trabajo del emigrante Vitalii (Spb209) en su red de 16 miembros (Tabla 3).

Lo que vemos es que había una persona que era compañero de trabajo pero no amigo y una persona que era amigo pero no compañero de trabajo pero la mayoría eran ambas cosas a la vez y Vitalii les había conocido a todos en el trabajo ${ }^{24}$.

\footnotetext{
22 En cifras absolutas, 50 de 149 para emigrantes y 5 de 24 para nativos.

${ }^{23}$ En cifras absolutas, 50 de 83 para emigrantes y 5 de 32 para nativos.

24 En general, los emigrantes tenían un mayor número de relaciones solapadas (o múltiples), con una persona contando como amigo, vecino y compañero de trabajo a la vez.
} 


\begin{tabular}{lccc}
\hline \multicolumn{1}{c}{ Miembro de la red } & $\begin{array}{c}\text { Compañeros de } \\
\text { trabajo }\end{array}$ & Amigo & $\begin{array}{c}\text { Lugar de } \\
\text { conocimiento }\end{array}$ \\
\hline Oleg & + & + & Trabajo \\
Ivan & + & + & Trabajo \\
Elena & + & + & Trabajo \\
Andrei & + & + & Trabajo \\
Vladimir & & + & Trabajo \\
Igor & + & & Trabajo \\
\hline
\end{tabular}

Tabla 3. Compañeros de trabajo y amigos en la red personal de Vitalii.

\begin{tabular}{lccc}
\hline $\begin{array}{c}\text { Compañero de } \\
\text { trabajo }\end{array}$ & $\begin{array}{c}\text { Le puede pedir ayuda } \\
\text { en pequeñas } \\
\text { reparaciones o } \\
\text { arreglar cosas en } \\
\text { casa }\end{array}$ & $\begin{array}{c}\text { Le puede pedir una } \\
\text { gran cantidad de } \\
\text { dinero }\end{array}$ & $\begin{array}{c}\text { Ha recibido o hecho } \\
\text { algún favor en los } \\
\text { últimos tres años }\end{array}$ \\
\hline Vadim & + & & + \\
Petr & & & + \\
Gennadii & + & + \\
Arsenii & + & + \\
Fedor & & + \\
Ivan & & \\
Anatolii & & \\
Mikhail & & + \\
\hline
\end{tabular}

Tabla 4. Los compañeros de trabajo como fuente de apoyo material en la red personal de Oleg.

\section{Los compañeros de trabajo como fuente de apoyo material}

Nuestro séptimo y último indicador examina hasta qué punto los compañeros de trabajo de nuestros encuestados se daban apoyo material unos a otros. Esta dimensión es importante ya que las nóminas necesitan complementarse a menudo con varias formas informales de apoyo para asegurar la convivencia (véase por ejemplo Alasheev y Kiblitskaya, 1996; Clément, 2003; Ledeneva, 1998; Lonkila, 1997; Salmi, 2003a). En nuestro cuestionario sobre redes pedimos a cada encuestado que diera una lista de personas capaces de ayudarle en pequeñas reparaciones, a quienes pudieran acudir si necesitaban una gran suma de dinero o con los que habían intercambiado favores en los últimos tres años. Los resultados muestran que los compañeros de trabajo eran mucho más importantes como 
compañeros reales o potenciales para los emigrantes ( $32 \%$ del apoyo material venía de los compañeros de trabajo) que para los nativos $(15 \%)^{25}$.

Oleg (Spb207), un trabajador emigrante mencionado anteriormente, nombró a ocho compañeros de trabajo en su red de 15 miembros, y todos menos uno le podían dar ese tipo de apoyo (Tabla 4). Había tres trabajadores en la red de Oleg a los que podía pedir ayuda para reparaciones menores, tres a los que podía pedir una gran cantidad de dinero y dos eran personas con las que se había intercambiado favores en los últimos tres años. Lo que aún es más interesante es que estos compañeros de trabajo eran los únicos que Oleg nombraba al respecto; no mencionaba ni a parientes ni a amigos. Todos los indicadores mencionados anteriormente se resumen en la Tabla 5.

\begin{tabular}{lccc}
\hline \multicolumn{1}{c}{ Indicador } & $\begin{array}{c}\text { Emigrantes } \\
(\mathbf{\%})\end{array}$ & $\begin{array}{c}\text { Nativos } \\
\text { (\%) }\end{array}$ & $\begin{array}{c}\text { Todos } \\
\text { (\%) }\end{array}$ \\
\hline El trabajo como lugar donde establecer lazos sociales & 42 & 22 & 37 \\
Conocer a la futura esposa en el trabajo & 52 & 14 & 44 \\
Proporción de compañeros de trabajo & 38 & 20 & 34 \\
Quedar con compañeros de trabajo fuera del trabajo & 54 & 38 & 52 \\
Compañeros de trabajo - amigos de compañeros de & & 21 & 32 \\
trabajo & 34 & 16 & 47 \\
Compañeros de trabajo - amigos de amigos & 59 & 15 & 22 \\
Apoyo material por parte de compañeros de trabajo & 32 & & \\
\hline
\end{tabular}

Tabla 5. Resumen de indicadores.

\section{El trabajo como canal principal para la formación de redes de emigrantes}

Hasta ahora hemos visto que los compañeros de trabajo son mucho más significativos para los emigrantes que para los nativos entre nuestros sujetos. ¿Por qué? Para poder responder a esta pregunta, necesitamos explorar la formación de relaciones sociales y examinar qué canales son posibles, probables o improbables a la hora de establecer nuevas relaciones sociales en un contexto particular. En referencia con otro contexto, en su estudio de la formación de redes en Turín, Eve (1998, pp. 46 - 51) argumenta que aunque se pueden hacer amigos y conocidos nuevos en un número infinito de circunstancias, a la práctica las redes no se expanden al azar, sino por medio de un número limitado de canales.

\footnotetext{
${ }^{25}$ Las cifras absolutas de compañeros de trabajo dando apoyo eran 38 de 120 miembros de la red para emigrantes, a diferencia de los 5 de 34 para nativos.
} 
Dos canales -familia y ocupación- son especialmente importantes. Eve señala que sin conocer en detalle qué red familiar contribuye o no contribuye, no podemos entender el perfil ocupacional de la red de un individuo (Eve trata la homogeneidad ocupacional, pero su argumento se puede aplicar al examen de la existencia o no existencia de compañeros de trabajo). Los emigrantes en particular se hallan en una posición en la que necesitan construir una nueva red en una nueva ubicación, pero sólo cuentan con medios limitados para hacerlo (Eve, 2002a, p. 2). Lo primero que hay que señalar sobre nuestros emigrantes es que la mayoría no tenían familiares en su nueva ubicación. Esto significa, en primer lugar, que uno de los principales canales para ampliar la red - la familia- era inexistente ${ }^{26}$.

El hecho de que la familia viva en un lugar distinto no significa necesariamente que no tenga impacto en la red (por no mencionar el contacto y la comunicación). De hecho, la investigación reciente sobre migración ha dado énfasis al hecho de que la migración transforma los lazos sociales existentes entre la gente en las comunidades de origen y destino pero no los rompe (Brown, 2002, pp. 11, 17) ${ }^{27}$. Hasta qué punto pueden mantenerse estos lazos, sin embargo, depende probablemente de una serie de factores institucionales y económicos que facilitan o entorpecen la comunicación en la distancia geográfica y siempre debería de examinarse de forma empírica. Por eso cuando examinamos los lugares de residencia de los miembros de la red, encontramos que las redes de apoyo de los emigrantes se centraban en gran parte en San Petersburgo y que pocos miembros vivían fuera de la ciudad. De hecho no había casi diferencia entre emigrantes y nativos a este respecto, cosa que sugiere que la ruptura con la red social previa de los emigrantes era casi completa y quedaban pocos vínculos con sus lugares de

\footnotetext{
${ }^{26}$ Una minoría, 8 trabajadores emigrantes, tenían un pariente que vivía en Leningrado; normalmente era un hermano mayor que se había mudado antes que ellos, mientras que los padres se habían quedado en su pueblo natal. Estos familiares a menudo les ayudaban con un alojamiento provisional o a encontrar trabajo, y éste era un factor muy importante para mudarse a Leningrado. Como estos parientes normalmente eran otros trabajadores y la mayoría trabajaban en la fábrica Kirov, era difícil que les presentaran miembros de redes no relacionados con el trabajo. La importancia de la migración en cadena (que a menudo lleva a empleo en cadena; véase M. Grieco, 1987, p. 51) y/ o redes en la nueva ubicación se ha documentado en la mayoría de estudios (véase por ejemplo M. Grieco, 1987; Eve, 2002a, pp. 7 - 8; Moretti, 1999; Shah y Menon, 1999; Bauer y Zimmermann, 1997; para Rusia ver Pilkington, 1998, pp. 109, 125, 138; Vitukhnovskaya, 2000, p. 112; Gerasimova y Chuikina, 2000, p. 48).

27 Un buen ejemplo de esto son los trabajadores emigrantes finlandeses de nuestros datos, que están estrechamente ligados su pueblo de origen, donde conservan casas de veraneo que ellos y su familia utilizan regularmente. En Finlandia, mudarse del campo a la ciudad no significa necesariamente cortar los lazos o debilitarlos: cruzar la frontera entre el campo y la ciudad es mucho menos drástico que en la Rusia (soviética) (Castrén, 2001, p. 72; véase también Alapuro, 1998).
} 
origen $^{28}$. La situación post-soviética es especial por el hecho de que muchos familiares se hallaron viviendo en el extranjero, en Bielorrusia o Ucrania, por ejemplo, y eso entrañaba que el viaje y la burocracia implicada eran muy complejos. Como dijo el encuestado Oleg (Spb207): “Antes iba (a Bielorusia a visitar a su familia) a menudo, una vez al año, y ellos venían (a visitarme). Pero ahora el dinero es un problema. No lo sé, hace cuatro años que no voy. Es duro". En el momento de realizar este estudio se llamaban por teléfono y se escribían cartas pero "no es lo mismo, es algo verbal".

Los contactos cara a cara, que son esenciales para mantener los lazos con la familia dispersa no se producen (véase Urry, 2003). Por ello llegamos a la conclusión que la ausencia de familia contribuye a que las relaciones en el lugar de trabajo sean tan significativas para los trabajadores emigrantes ${ }^{29}$.

Una persona que puede aportar gente no relacionada con el trabajo a la red de los emigrantes es su esposa (véase Castrén, 2001). En su estudio de las redes de 40 profesores en San Petersburgo y de 38 en Helsinki, Castrén encontró, sin embargo, que el papel de la esposa a la hora de introducir a miembros en la red era casi nulo en San Petersburgo. Aunque había una excepción. Si el emigrante se casaba con una nativa de San Petersburgo, la esposa nativa suministraba muchos más miembros a la red que en cualquier otro caso (Castrén, 2001, pp. 70-73), pero aunque eso era muy importante para aquellos que se casaban con una lugareña, esto no era habitual. En el estudio de Castrén sólo tres (de 10 profesores emigrantes) lo habían hecho. Ocurre lo mismo con nuestros trabajadores de fábricas, con sólo un encuestado entre los emigrantes que se hubiera casado con una lugareña, mientras que los otros se habían casado con emigrantes. Estos ejemplos sugieren que los emigrantes tienden a conocer y casarse con otros emigrantes, pero harían falta otros estudios para confirmar o refutar esta hipótesis. Además, a menudo las esposas trabajan en el mismo puesto (que era el caso para

\footnotetext{
28 Aunque varios generadores de nombre eran propensos a generar miembros de red próximos geográficamente (ayuda para cuidar a los niños es un buen ejemplo), los encuestados pudieron añadir a personas a las que no habían mencionado anteriormente pero que consideraban importantes (independientemente de la distancia geográfica).

29 En su estudio de Leningrado en los años treinta, Gerasimova y Chuikina argumentaban que la diferencia principal entre los trabajadores nativos y emigrantes era la ausencia de parientes representando a las generaciones mayores entre los emigrantes. En contraste con nuestro estudio, hallaron que los compañeros de trabajo (y vecinos) eran igual de importantes para los emigrantes como para los nativos. Sin embargo es difícil comparar los resultados porque la metodología usada es muy distinta; su estudio se basaba en entrevistas con gente mayor que hablaban de su vida en los años treinta.
} 
más de la mitad de los emigrantes que estaban casados o lo habían estado) ${ }^{30}$. La importancia del lugar de trabajo como escenario para hacer nuevas amistades era mayor en la era soviética porque había pocos lugares públicos como clubes y cafeterías y a la gente le faltaba la confianza necesaria para iniciar relaciones en ellos (Shlapentokh, 1989, p. 133). Por lo tanto es probable que la esposa aporte unos miembros similares a la red -gente del trabajo, cosa que significa que la esposa no debilita si no que refuerza aún más la importancia de las relaciones de trabajo para los emigrantes.

Existen otros canales donde los emigrantes - al menos en un principio- son capaces de establecer relaciones que no estén relacionadas con el lugar de trabajo, y vamos a tratar a tres importantes: vecinos, organizaciones y actividades de tiempo libre (véase también Eve, 1998).

En primer lugar, tanto emigrantes como nativos contaban con una proporción significativa de vecinos en sus redes: $20 \%$ y $16 \%$. Pero el hecho de que los historiales de vivienda de la mayoría de emigrantes estuvieran conectados con la fábrica significa que la mayoría de sus vecinos - pasados y presentes- eran compañeros de trabajo (dependiendo de si su nuevo piso era una concesión de la fábrica o del ayuntamiento). De nuevo, es poco probable que los vecinos disminuyan la importancia del lugar de trabajo como campo para establecer conexiones. En segundo lugar, es también poco probable que las actividades organizativas aporten nuevos miembros a las redes porque, excepto el sindicato, nuestros encuestados declararon no participar en ninguna. La mayor parte de los miembros del sindicato no participaban de forma activa pero incluso si lo hacían, el sindicato no hacía disminuir, si no que aumentaba el número de vínculos laborales. En general, la participación rusa en las "organizaciones horizontales" es escasa. En su estudio de la acción colectiva en Helsinki y San Petersburgo basado en los mismos datos que el estudio de Castrén (2001), Alapuro y Lonkila (2000) hallaron que la mayoría de profesores finlandeses participaban en actividades de asociaciones formales, mientras que los rusos pocas veces lo hacían, aunque organizaban eventos y celebraciones en su lugar de trabajo: la escuela.

En tercer lugar, hay tres cosas que son muy importantes para el tiempo libre de los trabajadores: el dacha (o huerto), ir a buscar setas y la pesca. Pero es poco

\footnotetext{
30 Esto contrasta de nuevo con los encuestados finlandeses, muchos de los cuales habían conocido a sus esposas en pubs o lugares similares. Estas esposas podían introducir en las redes de su marido a personas que no eran compañeros de trabajo.
} 
probable que estas actividades atraigan a personas de fuera del trabajo a las redes de los emigrantes (ni siquiera el dacha si lo han obtenido de la fábrica porque lo más seguro es que sus vecinos de huerto sean otros trabajadores de la fábrica). Con todo, parece que la vida social del emigrante, especialmente en el pasado, se centraba en el lugar de trabajo: solían hacer picnics con sus compañeros de trabajo y sus familias, recogían dinero para excursiones, etc. Incluso entonces, se pasaba mucho tiempo libre ya fuera con la familia o bebiendo con los compañeros de trabajo después de la jornada laboral.

Para concluir, debemos volver a la cuestión de Eve (1998, pp. 44-45): ¿Cómo se forman o dejan de formar las redes? Responder a esta pregunta no sólo conlleva considerar a aquellos medios sociales influyentes si no también aquellos que, por una u otra razón, no produjeron nuevos miembros en un contexto específico. Podemos comprobar que los otros campos fuera del trabajo, o bien no existen en la vida de nuestros encuestados (como las actividades organizadas o la familia) o bien están relacionados con el trabajo (como la esposa, los vecinos, las aficiones y el tiempo libre).

\section{Conclusiones}

En este artículo hemos argumentado, en primer lugar, que a pesar de los cambios institucionales, el colectivo obrero sigue ejerciendo un impacto importante sobre las vidas diarias de los trabajadores en la era post-soviética, tanto dentro como fuera de la fábrica ${ }^{31}$. A nivel de vínculos sociales informales, el rol del colectivo obrero sigue siendo importante y la interacción con los compañeros de trabajo es todavía frecuente. Algunos de los encuestados, como los mineros de Kuzbass en el estudio de Ashwin (1999a), se lamentaban de que las relaciones ya no fueran tan estrechas como antes o las recordaban con nostalgia. Aunque esto no les impedía describir el colectivo como "bueno", "amistoso" o "normal" al mismo tiempo.

En segundo lugar, nuestros resultados sugieren que los vínculos informales dentro del colectivo son todavía más significativos para los trabajadores emigrantes que para aquellos nacidos en San Petersburgo, aunque la migración tuviera lugar hace décadas. Nuestro análisis reveló que esto podía explicarse examinando de cerca el proceso migratorio: a falta de otros canales para adaptarse a la nueva vida en la metrópolis, los nuevos lazos que los emigrantes crearon en la ciudad estaban

\footnotetext{
${ }^{31}$ Cuando comparamos los encuestados de San Petersburgo con los de Helsinki, hallamos que todos los rusos establecían muchos más lazos relacionados con el lugar de trabajo que los de Helsinki.
} 
relacionados en su mayoría con el lugar de trabajo. La importancia especial de la migración se refleja de varias formas: para los emigrantes, el trabajo es un lugar importante donde establecer nuevas relaciones en general y donde conocer a su futura esposa en particular; los compañeros de trabajo constituyen gran parte de la red; quedan con los compañeros de trabajo fuera de él; los compañeros de trabajo son, a menudo, también amigos, y la mayoría de los amigos son indicadores de compañero de trabajo (1-6).

Aún más, mientras que el rol institucional del colectivo en términos de concesión de beneficios ha disminuido, no se puede decir lo mismo sobre la ayuda informal de compañeros de trabajo, ya que el apoyo material de los compañeros de trabajo es especialmente importante para nuestros encuestados en San Petersburgo (indicador 7). A diferencia de Ashwin (1999a, p. 169), encontramos que las estrategias individuales de supervivencia también incluyen a los compañeros de trabajo, no sólo a parientes y amigos, y que las relaciones sociales de los emigrantes en particular estaban lejos de ser independientes del colectivo obrero. Al contrario, el colectivo está, como hemos mostrado, incrustado a menudo en las relaciones familiares y de amistad.

Que la migración convierte el lugar de trabajo en algo más importante parece a priori un hallazgo trivial, casi inevitable; pero no lo es por lo menos en dos aspectos. El primero, que las redes personales de los trabajadores continúan fuertemente marcadas por su entorno migratorio, aunque la migración se haya producido décadas atrás; que esto sea así no es algo obvio. Aunque los encuestados han trabajado y vivido en San Petersburgo entre 20 y 40 años, el tiempo de residencia no ha acabado con la dependencia original. En segundo lugar, el impacto de la migración siempre es específico en el contexto. De hecho, la migración en sí no es explicación suficiente. Lo importante es el tipo de migración (véase también E. Grieco, 2002). El tipo soviético contaba con una serie de características que la distinguían de sus equivalente Occidentales, como las restricciones a la hora de elegir el lugar de residencia y la falta de espacios públicos de confianza (como pubs y bares) para realizar nuevas conexiones. Cuando comparamos el caso soviético con el finlandés, se ve claro que la migración no produce de forma inevitable el mismo resultado: también hay emigrantes en los datos finlandeses pero sus redes no están construidas alrededor del trabajo. Esto no excluye la posibilidad de que las redes de los emigrantes finlandeses y los nativos de este país difieran en otros aspectos. De hecho, es posible que las redes de los emigrantes en cualquier lugar sean sistemáticamente distintas a las redes de 
los nativos, pero también es probable que difieran las formas y los mecanismos que las construyen ${ }^{32}$. Es también casi seguro que la migración es importante en otros aspectos, por ejemplo, como origen de la identidad. Debemos señalar que la migración toma distintas formas en distintos contextos y el contexto post-soviético es muy distinto al Occidental.

¿Qué implicaciones tiene para los emigrantes su fuerte dependencia del lugar de trabajo? Las "instalaciones de recepción” de la fábrica, la vivienda sobre todo, facilitaron las cosas a nuestros emigrantes y en muchos casos, hicieron posible la mudanza a la ciudad. Ésta es la principal diferencia con la actual re-emigración étnica de rusos que regresan de los países vecinos, ya que muchos de estos emigrantes no cuentan con el apoyo institucional, una vivienda decente o un trabajo (Pilkington, 1998, p. 123). Pero el hecho de que la vida social de nuestros emigrantes esté tan firmemente anclada en el lugar de trabajo tiene implicaciones menos favorables para ellos. Por ejemplo, existen pruebas que sugieren que las conexiones personales siguen siendo importantes en la era post-soviética, por ejemplo a la hora de encontrar trabajo (Clarke, 1999, pp. 222-237; Clarke y Kabalina, 2000; Tartakovskaya y Ashwin, 2005; Yakubovich y Kozina, 2000), conseguir atención sanitaria (Brown y Rusinova, 1997; Rivkin-Fish, 1997; Salmi, 2003a), educación (Lonkila, 1998), negocios (Gustafsson, 2003; Asta Salmi, 1999) y en muchos otros campos (Borén, 2003; Ledeneva, 1998; Lonkila, 1999a, 1999b; Rose, 1998; Salmi, 2003b). El hecho de que la red social de apoyo esté conectada de forma tan estrecha a un solo medio social, también significa que las redes son, a nivel social e incluso a nivel laboral relativamente homogéneas. Esto probablemente sugiere que los emigrantes, en gran medida, no tienen acceso a otros medios y redes sociales útiles y más de "clase media", como contactos con profesores y doctores (véase Salmi, 2003a).

¿Se pueden explicar las diferencias observadas entre emigrantes y nativos con el impacto de una tercera variable, como la duración del empleo en la fábrica? Primero, el hecho de que cinco de nuestros diez trabajadores nativos contra dos de 28 emigrantes fueran nuevos en la fábrica ${ }^{33}$ explicaría la escasa presencia de compañeros de trabajo en las redes nativas. Aunque la naturaleza y el tamaño de

\footnotetext{
${ }^{32}$ Agradecemos a Michael Eve (comunicación personal) que haya señalado este punto.

33 Eso significa que llevaban trabajando en la fábrica cuatro años o menos. Entre todos, 13 encuestados habían trabajado en el departamento cuatro años o menos. Seis de ellos habían trabajado también en otros departamentos de la fábrica durante 20 años o más y por lo tanto no se pueden incluir en la categoría de "recién llegados".
} 
nuestros datos no permiten un análisis a fondo, excluimos a los siete recién llegados y recalculamos los indicadores para los restantes cinco nativos y 26 emigrantes. Los 31 trabajadores habían trabajado en la planta durante más de 16 años. Los resultados mostraron que, en general, las diferencias persistían, que la distancia entre emigrantes y nativos era menor para los indicadores 1-3 y 6, igual para el indicador 4 y aumentaba en los indicadores 5 y 6 .

En segundo lugar, como todas las mujeres encuestadas eran emigrantes, el efecto combinado de género y migración no puede considerarse de forma sistemática en nuestros datos. Sin embargo, calculamos los mismos indicadores para las mujeres encuestadas para investigar si había diferencias drásticas. En resumen, las cifras para mujeres emigrantes eran algo más bajas que para hombres emigrantes (excepto en dos indicadores, en que eran superiores), pero superiores a las de los hombres nativos. Aunque estos datos de red no revelan diferencias de género significativas, este aspecto merece claramente un estudio adicional.

En tercer lugar, es muy probable que la edad y la etapa de la vida ejerzan un impacto importante en la migración. La mayoría de nuestros trabajadores emigrantes se habían mudado a Leningrado siendo jóvenes adultos pero antes de formar una familia (véase también Piipponen, 2004, para un debate sobre "la generación soviética"). Las redes de aquellos que migraron durante la infancia serían muy distintas, al haber establecido relaciones en la escuela o durante los estudios, cosa que diversificaría la red, que no estaría tan centrada alrededor del trabajo.

Finalmente, San Petersburgo puede tener una importancia como escenario. El mito cultural de la ciudad es parte importante de su patrimonio y se suele señalar la superioridad cultural de la ciudad (véase Hellberg-Hirn, 2003). Por lo tanto, el ciudadano nacido en San Petersburgo cuenta con un valor cultural importante, que probablemente se refleja en su actitud hacia los emigrantes y nativos ${ }^{34}$ (véase también Gerasimovay Chuikina, 2000). Es necesario profundizar en las investigaciones para ver si la migración tuvo el mismo impacto en las redes sociales en el resto de Rusia.

\footnotetext{
34 Para poner un ejemplo: En las celebraciones del tricentenario de San Petersburgo, Sofia Tchouikina fue testigo del siguiente episodio. Las celebraciones del día se iniciaron con el desfile de la banda militar en Nevsky Prospekt. Un espectador se irritó con una mujer que empujaba a sus vecinos y la increpó: “¿Por qué empujas, mujer? Tú no eres de Leningrado". "Te equivocas, soy de Leningrado". "De primera generación, supongo. Si fueras de tercera generación, no empujarías para llegar a primera fila" (en Hellberg-Hirn, 2000, p. 287).
} 


\section{Bibliografía}

Alapuro, Risto, 'Continuités et discontinuitiés des réseaux d'enseignants à Helsinki et Paris', en Maurizio Gribaudi (ed.), Espaces, temporalités, stratifications: Exercises méthodologiques sur les réseau sociaux (Paris, Editions de l'Ecole des Hautes Etudes en Sciences Sociales, 1998), pp. $121-142$.

Alapuro, Risto y Lonkila, Markku, 'Networks, Identity and (In)action: A Comparison Between Russian and Finnish Teachers', European Societies, 2, 1, 2000, pp. 65 90.

Alapuro, Risto, Liikanen, Ilkka y Lonkila, Markku (eds), Beyond Post-Soviet Transition: Micro Perspectives on Challenge and Survival in Russia and Estonia (Helsinki, Kikimora Publications, 2004).

Alasheev, Sergei y Kiblitskaya, Marina, 'How to Survive on a Russian's Wage', en Simon Clarke (ed.), Labour Relations in Transition: Wages, Employment and Industrial Conflict in Russia (Cheltenham, Edward Elgar, 1996), pp. 99 - 118.

Ashwin, Sarah, 'Endless Patience: Explaining Soviet and Post-Soviet Social Stability', Communist and Post-Communist Studies, 31, 2, 1998, pp. 187 - 198.

Ashwin, Sarah, Russian Workers: The Anatomy of Patience (Manchester, Manchester University Press, 1999a).

Ashwin, Sarah, 'Redefining the Collective: Russian Mineworkers in Transition', en Michael Burawoy y Katherine Verdery (eds), Uncertain Transition: Ethnographies of Change in the Postsocialist World (Lanham, MD, Rowman y Littlefield, 1999b), pp. $245-271$.

Ashwin, Sarah (ed.), Gender, State and Society in Soviet and Post-Soviet Russia (London, Routledge, 2000).

Badyshtova, I.M., 'Spetsifika domokhozyaistv trudovykh migrantov v Rossii', Sotsiologicheskie issledovaniya, 28, 9, 2002, pp. 83 - 90.

Bauer, Thomas y Zimmermann, Klaus F., 'Network Migration of Ethnic Germans', International Migration Review, 31, 1, 1997, pp. 143 - 149.

Berzin, B. y Panova, S., 'Propiska: "Za" i "Protiv" ', Sotsiologicheskie issledovaniya, 17, 11, 1990, pp. $96-98$.

Borén, Thomas, 'What are Friends for? Rationales of Informal Exchange in Russian Everyday Life', en Karl-Olov Arnstberg y Thomas Borén (eds), Everyday Economy in Russia, Poland and Latvia (Stockholm, Södertörn Academic Studies, Almqvist \& Wiksell International, 2003), pp. 21 - 36.

Boyd, Monica, 'Family and Personal Network in International Migration: Recent Developments and New Agendas', International Migration Review, 23, 3, 1989, pp. $638-670$.

Brown, David L., 'Migration and Community: Social Networks in a Multilevel World', Rural Sociology, 67, 1, 2002, pp. 1 - 23.

Brown, Julie y Rusinova, Nina L., 'Russian Medical Care in the 1990s: A User's Perspective', Social Science \& Medicine, 45, 8, 1997, pp. 1265 - 1276. 
Buckley, Cynthia, 'The Myth of Managed Migration: Migration Control and Market in the Soviet Period', Slavic Review, 54, 4, 1995, pp. 896 - 916.

Burawoy, Michael y Krotov, Pavel, 'The Soviet Transition from Socialism to Capitalism: Worker Control and Economic Bargaining in the Wood Industry', in Simon Clarke, Peter Fairbrother,

Michael Burawoy y Pavel Krotov (eds), What about the Workers? Workers and the Transition to Capitalism in Russia (London and New York, Verso, 1993), pp. 56 90.

Burawoy, Michael y Verdery, Katherine, 'Introduction', en Michael Burawoy y Katherine Verdery (eds), Uncertain Transition: Ethnographies of Change in the Postsocialist World (Lanham, MD., Rowman y Littlefield, 1999), pp. 1 - 17.

Castrén, Anna-Maija, Perhe ja työHelsingissä ja Pietarissa: Elämänpiirit ja yhteiskunta opettajien sosiaalisissa verkostoissa (Family and Work in Helsinki and St. Petersburg: Social Circles and Societies in the Social Networks of Teachers) (Helsinki, SKS, 2001).

Clarke, Simon, 'Formal and Informal Relations in Soviet Industrial Production', en Simon Clarke (ed.), Management and Industry in Russia: Formal and Informal Relations in the Period of Transition (Cheltenham, Edward Elgar, 1995a), pp. 1 27.

Clarke, Simon (ed.), Management and Industry in Russia: Formal and Informal Relations in the Period of Transition (Cheltenham, Edward Elgar, 1995b).

Clarke, Simon (ed.), Conflict and Change in the Russian Industrial Enterprise (Cheltenham, Edward Elgar, 1996a).

Clarke, Simon (ed.), Labour Relations in Transition: Wages, Employment and Industrial Conflict in Russia (Cheltenham, Edward Elgar, 1996b).

Clarke, Simon (ed.), The Russian Enterprise in Transition: Case Studies (Cheltenham, Edward Elgar, 1996c).

Clarke, Simon, The Formation of a Labour Market in Russia (Cheltenham, Edward Elgar, 1999).

Clarke, Simon y Kabalina, Veronika, 'The New Private Sector in the Russian Labour Market', Europe-Asia Studies, 52, 1, 2000 pp. 7 - 32.

Cle' ment, Karine [Kleman, Karin], 'Neformal'nye praktiki rossiiskikh rabochikh', Sotsiologicheskie issledovaniya, 30, 5, 2003, pp. 62 - 72.

Dolgikh, E., 'Migratsionnye protsessy skvoz' prizmu individual'nogo zhiznennogo opyta', en V. Semenova y E. Foteeva (eds), Sud'by lyudei: Rossiya XX vek (Moscow, Institut sotsiologii RAN, 1996), pp. 355 - 372.

Eve, Michael, 'Qui se ressemble s'assemble? Les sources d'homogénéité à Turin', en Maurizio Gribaudi (ed.), Espaces, temporalite's, stratifications: Exercices sur les réseaux sociaux (Paris, Éditions de l'École des Hautes Études en Sciences Sociales, 1998), pp. $43-69$. 
Eve, Michael, 'Una sociologia degli altri e un'altra sociologia: La tradizioni di studio dell'immigrazione', Quaderni Storici, 106, April 2001.

Eve, Michael, 'Migration as a Sociological Variable'. Manuscrito inédito, 2002a. Eve, Michael, 'Les deux traditions d'analyse des réseaux', Réseaux, 20, 115, 2002b, pp. $183-212$.

Fassman, Heinz y Münz, Rainer, 'European East-West Migration, 1945 - 1992', International Migration Review, 28, 3, 1994, pp. 520 - 538.

Fischer, Claude S., To Dwell Among Friends: Personal Networks in Town and City (Chicago, University of Chicago Press, 1982).

Fitzpatrick, Sheila, Stalin's Peasants: Resistance and Survival in the Russian Village after Collectivization (Oxford, Oxford University Press, 1994).

Flowerdew, Robin, 'Introduction: Internal Migration in the Contemporary World', Regional Studies, 38, 6, 2004, pp. 615 - 616.

Gang, Ira N. y Stuart, Robert C., 'Mobility Where Mobility Is Illegal: Internal Migration and City Growth in the Soviet Union', Journal of Population Economics, 12, 1, 1999, pp. $117-134$.

Gerasimova, Katerina y Chuikina, Sofia, ‘Ot kapitalisticheskogo Peterburga k sotsialisticheskomu Leningradu: Izmenenie sotsial'no-prostranstvennoi struktury goroda v 30-e gody', in Timo

Vihavainen (ed.), Normy i tsennosti povsednevnoi zhizni: Stanovlenie sotsialisticheskogo obraza zhizni v Rossii, 1920 - 1930 Gody (St Petersburg, Zhurnal Neva, 2000), pp. 27 - 74.

Grant, Jonathan A., Big Business in Russia: The Putilov Company in Late Imperial Russia, 1868 - 1917 (Pittsburgh, University of Pittsburgh Press, 1999).

Gribaudi, Maurizio (ed.), Espaces, temporalite's, stratification: Exercises méthodologiques sur les réseaux sociaux (Paris, Editions de l'Ecole des Hautes Etudes en Sciences Sociales, 1998).

Grieco, Elizabeth M., 'The Effects of Migration on the Establishment of Networks: Caste Disintegration and Reformation Among the Indians of Fiji', International Migration Review, 32, 3, 1998, pp. 704 - 736.

Grieco, Margaret, Keeping it in the Family: Social Networks and Employment Chance (London and New York, Tavistock Publications, 1987).

Gustafsson, Pär, 'Foreign Companies and Everyday Economy in Russia', en KarlOlov Arnstberg y Thomas Borén (eds), Everyday Economy in Russia, Poland and Latvia (Stockholm, Södertörn Academic Studies, Almqvist \& Wiksell International, 2003), pp. $71-88$.

Hellberg-Hirn, Elena, Imperial Imprints: Post-Soviet St Petersburg (Helsinki, SKS, 2003). Höjdestrand, Tova, 'The Soviet-Russian Production of Homelessness: Propiska, Housing, Privatisation', 2003, Electronic document, http://www.anthrobase.com/Txt/H/Hoejdestrand_T_01.htm, downloaded 5 March 2004. 
Kemper, Franz-Josef, 'Internal Migration in Eastern and Western Germany: Convergence or Divergence of Spatial Trends after Unification', Regional Studies, $38,6,2004$, pp. $659-678$.

Kiblitskaya, Marina, ““ Once We Were Kings”: Male Experiences of Loss of Status at Work in Post- Communist Russia', en Sarah Ashwin (ed.), Gender, State and Society in Soviet and Post-Soviet Russia (London, Routledge, 2000), pp. 90 - 104.

Kulu, Hill y Billari, Francesco, C., 'Multilevel Analysis of Internal Migration in a Transitional Country: The Case of Estonia', Regional Studies, 38, 6, 2004, pp. 679 - 696.

Kulu, Hill y Tammaru, Tiit, 'Ethnic Return Migration from the East and the West: The Case of Estonia in the 1990s', Europe-Asia Studies, 52, 2, 2000, pp. 349 369.

Ledeneva, Alena V., Russia's Economy of Favours: Blat, Networking and Informal Exchange (Cambridge, Cambridge University Press, 1998).

Loeber, Dietrich Andre, 'Limitchiki: On the Legal Status of Migrant Workers in Large Soviet Cities', Soviet Union, 11, 3, 1984, pp. 301 - 311.

Lonkila, Markku, 'Informal Exchange Relations in Post-Soviet Russia: A Comparative Perspective', Sociological Research Online, 2, 2, 1997 www. socresonline.org.uk/socresonline/2/2/9. html.

Lonkila, Markku, 'The Social Meaning of Work: Aspects of the Teaching Profession in Post-Soviet Russia', Europe-Asia Studies, 50, 4, 1998, pp. 699 - 712.

Lonkila, Markku, Social Networks in Post-Soviet Russia: Continuity and Change in the Everyday Life of St. Petersburg Teachers (Helsinki, Kikimora Publications, 1999a).

Lonkila, Markku, 'Post-Soviet Russia: A Society of Networks', in Markku Kangaspuro (ed.), Russia: More Different than Most (Helsinki, Kikimora Publications, 1999b), pp. $99-112$.

Lonkila, Markku y Piipponen, Minna, 'Social Networks and Civic Culture in Estonia and North-Western Russia', Joensuu, University of Joensuu, Reports of Karelian Institute, 3, 2002.

Maksimov, B.l., 'Trudovye organizatsii kak sub"ekty obshchestvennoi zhizni: Dinamika izmenenii', Zhurnal sotsiologii i sotsial'noi antropologii, 10, 2, 2000, pp. $92-108$.

Massey, Douglas, 'Social Structure, Household Strategies, and the Cumulative Causation of Migration', Population Index, 56, 1, 1990, pp. 3 - 26.

Miroshnichenko, N.S. y Maksimov, B.I., ‘Privatizatsiya Kirovskogo zavoda kak protsess', Sotsiologicheskie issledovaniya, 21, 11, 1994, pp. 30 - 38.

Mitchneck, Beth y Plane, David, 'Migration Patterns During a Period of Political and Economic Shocks in the Former Soviet Union: A Case Study of Yaroslavl' Oblast', Professional Geographer, 47, 1, 1995, pp. 17 - 30. 
Monousova, Galina y Guskova, Natalya, 'Internal Mobility and the Restructuring of Labour', en Simon Clarke (ed.), Labour Relations in Transition: Wages, Employment and Industrial Conflict in Russia (Cheltenham, Edward Elgar, 1996), pp. 82 - 98.

Moretti, Enrico, 'Social Networks and Migrations: Italy 1876 - 1913', International Migration Review, 33, 3, 1999, pp. 640 - 657.

Morrison, Claudio y Schwartz, Gregory, 'Managing the Labour Collective: Wage Systems in the Russian Industrial Enterprise', Europe-Asia Studies, 55, 4, 2003, pp. $553-574$.

Morton, Henry, 'Who Gets What, When and How? Housing in the Soviet Union', Soviet Studies, 32, 2,1980, pp. 235 - 259.

Nicholson, Beryl, 'The Tractor, the Shop and the Filling Station: Work Migration as Self-help Development in Albania', Europe-Asia Studies, 56, 6, 2004, pp. 877 890.

Nikula, Jouko, From State-Dependency to Genuine Worker Movement? The Working Class in Socialism and Post-Socialism (Tampere, Tampere University Press, 1997).

Osipov, A., 'Motivy pereseleniya iz derevni v gorod', Sotsiologicheskie issledovaniya, 15, 2, 1988, pp. $71-73$.

Piipponen, Minna, 'Työtraktoritehtaan työntekijöiden verkostoissa', I da"ntutkimus 9, 4, 2002, pp. $69-79$.

Piipponen, Minna, 'Work-related Ties in the Everyday Life of a Russian Karelian Mill Community', en Risto Alapuro, Ilkka Liikanen y Markku Lonkila (eds), Beyond PostSoviet Transition: Micro Perspectives on Challenge and Survival in Russia and Estonia (Helsinki, Kikimora Publications, 2004), pp. 64 - 83.

Pilkington, Hilary, Migration, Displacement and Identity in Post-Soviet Russia (London and New York, Routledge, 1998).

Popov, V., 'Pasportnaya sistema v SSSR', Sotsiologicheskie issledovaniya, 22, 8, 1995a, pp. 3 - 14.

Popov, V., 'Pasportnaya sistema v SSSR', Sotsiologicheskie issledovaniya, 22, 9, 1995b, pp. 3 - 13.

Portes, Alejandro, 'Economic Sociology and the Sociology of Immigration: A Conceptual Overview', in Alejandro Portes (ed.), The Economic Sociology of Immigration: Essays on Networks, Ethnicity, and Entrepreneurship (New York, Russell Sage Foundation, 1995), pp. 1 - 41.

Rivkin-Fish, Michele, 'Reproducing Russia: Women's Health and Moral Education in the Construction of a Post-Soviet Society', Doctoral thesis, Princeton University, 1997.

Rose, Richard, Getting Things Done in an Anti-Modern Society: Social Capital Networks in Russia (Glasgow, Studies in Public Policy No 304, Centre for the Studies of Public Policy, University of Strathclyde, 1998). 
Rotkirch, Anna, 'The Man Question: Loves and Lives in Late 20th Century Russia', Helsinki, University of Helsinki, Department of Social Policy Research Reports, 1, 2000.

Salmi, Anna-Maria, 'Bonds, Bottles, Blat and Banquets: Birthdays and Networks in Russia', Ethnologia Europaea, 30, 1, 2000, pp. 31 - 44.

Salmi, Anna-Maria, 'Health in Exchange: Teachers, Doctors, and the Strength of Informal Practices in Russia', Culture, Medicine and Psychiatry, 27, 2, 2003a, pp. $31-44$.

Salmi, Anna-Maria, 'Neighbours and the Everyday Economy', in Karl-Olov Arnstberg \& Thomas Borén (eds), Everyday Economy in Russia, Poland and Latvia (Stockholm, Södertörn Academic Studies, Almqvist y Wiksell International, 2003b), pp. $147-170$.

Salmi, Asta, 'Transformation in Russia: Emerging Markets or Evolving Networks?', en Markku Kangaspuro (ed.), Russia: More Different than Most (Helsinki, Kikimora Publications, 1999), pp. 137 - 168.

Shah, Nasra M. y Menon, Indu, 'Chain Migration Through the Social Network: Experience of Labour Migrants in Kuwait', International Migration, 37, 2, 1999, pp. $361-381$.

Shlapentokh, Vladimir, Public and Private Life of the Soviet People: Changing Values in Post-Stalin Russia (New York, Oxford University Press, 1989).

Sjöberg, Örjan y Tammaru, Tiit, 'Transitional Statistics: Internal Migration and Urban Growth in Post-Soviet Estonia', Europe-Asia Studies, 51, 5, 1999, pp. 821 842.

Tartakovskaya, I rina y Ashwin, Sarah, 'Who Benefits from Networks?', in Sarah Ashwin (ed.), Adapting to Russia's New Labour Market: Gender and Employment Strategy (UK, Routledge, 2005).

Tkach, Olga, 'The Phenomenom of the "Soviet Hereditary Worker": From Asseveration of Social Class Purity to Workers' Dynasty', in Timo Vihavainen (ed.), The Soviet Union - A Popular State? Studies on Popular Opinion in the USSR (St Petersburg, Evropeiskii Dom, 2001), pp. 162 - 179.

Urry, John, 'Social Networks, Travel and Talk', British Journal of Sociology, 54, 2, 2003, pp. 155 - 176.

Vitukhnovskaya, Marina, “" Starye" i "novye" gorozhane: migranty v Leningrade 1930-kh godov', in Timo Vihavainen (ed.), Normy i tsennosti povsednevnoi zhizni: Stanovlenie sotsialisticheskogo obraza zhizni v Rossii, 1920 - 1930 gody (St Petersburg, Zhurnal Neva, 2000), pp. 99 - 150.

Wegren, Stephen K., 'Rural Migration and Agrarian Reform in Russia: A Research Note', Europe- Asia Studies, 47, 5, 1995, pp. 877 - 889.

Wegren, Stephen y Drury, A. Cooper, 'Patterns of Internal Migration During the Russian Transition', Journal of Communist Studies and Transition Politics, 17, 4, 2001, pp. $15-42$. 
Yakubovich, Valery y Kozina, Irina, 'The Changing Significance of Ties: An Exploration of the Hiring Channels in the Russian Transitional Labor Market', International Sociology, 15, 3, 2000, pp. 479 - 501.

Zaslavsky, Victor, The Neo-Stalinist State: Class, Ethnicity and Consensus in Soviet Society (Brighton, Sussex, Harvester Press, 1982).

Zayonchkovskaya, Zhanna, 'Recent Migration Trends in Russia', in George J. Demko, Grigory Ioffe y Zhanna Zayonchkovskaya (eds), Population under Duress: The Geodemography of Post-Soviet Russia (Boulder, CO and Oxford, Westview Press, 1999), pp. $107-136$.

Zemtsov, Ilya, Encylopedia of Soviet Life (New Brunswick, NJ, Transaction Publishers, 1991). 